Article

\title{
Reduction of the Economic Risk by Adaptation Measures to Alleviate Heat Stress in Confined Buildings for Growing-Fattening Pigs Modelled by a Projection for Central Europe in 2030
}

\author{
Günther Schauberger 1,*D, Martin Schönhart ${ }^{2}$, Werner Zollitsch ${ }^{3}$, Stefan J. Hörtenhuber ${ }^{3} \mathbb{D}^{\mathbb{D}}$, Leopold Kirner ${ }^{4}$, \\ Christian Mikovits ${ }^{1,2}\left(\mathbb{D}\right.$, Johannes Baumgartner ${ }^{5}\left(\mathbb{D}\right.$, Martin Piringer ${ }^{6}\left(\mathbb{D}\right.$, Werner Knauder ${ }^{6}$, Ivonne Anders ${ }^{7,8}$, \\ Konrad Andre ${ }^{8}(\mathbb{D})$ and Isabel Hennig-Pauka ${ }^{9}$ (D)
}

check for updates

Citation: Schauberger, G.; Schönhart, M.; Zollitsch, W.; Hörtenhuber, S.J.;

Kirner, L.; Mikovits, C.; Baumgartner, J.; Piringer, M.; Knauder, W.; Anders, I.; et al. Reduction of the Economic Risk by Adaptation Measures to Alleviate Heat Stress in Confined Buildings for Growing-Fattening Pigs Modelled by a Projection for Central Europe in 2030. Agronomy 2022, 12, 248. https://doi.org/10.3390/ agronomy12020248

Academic Editor: José L. S. Pereira

Received: 28 December 2021

Accepted: 13 January 2022

Published: 19 January 2022

Publisher's Note: MDPI stays neutral with regard to jurisdictional claims in published maps and institutional affiliations.

Copyright: (c) 2022 by the authors. Licensee MDPI, Basel, Switzerland. This article is an open access article distributed under the terms and conditions of the Creative Commons Attribution (CC BY) license (https:// creativecommons.org/licenses/by/ $4.0 /)$.
1 WG Environmental Health, Unit for Physiology and Biophysics, University of Veterinary Medicine, 1210 Vienna, Austria; Christian.Mikovits@boku.ac.at

2 Institute for Sustainable Economic Development, University of Natural Resources and Life Sciences, 1180 Vienna, Austria; Martin.Schoenhart@boku.ac.at

3 Division of Livestock Sciences, Department of Sustainable Agricultural Systems, University of Natural Resources and Life Sciences, 1180 Vienna, Austria; Werner.Zollitsch@boku.ac.at (W.Z.); Stefan.Hoertenhuber@boku.ac.at (S.J.H.)

4 University College for Agrarian and Environmental Pedagogy, 1130 Vienna, Austria; leopold.kirner@haup.ac.at

5 Institute of Animal Welfare Science, University of Veterinary Medicine, 1210 Vienna, Austria; Johannes.Baumgartner@vetmeduni.ac.at

6 Department of Environmental Meteorology, Central Institute of Meteorology and Geodynamics, 1190 Vienna, Austria; martin1956@gmx.at (M.P.); Werner.Knauder@zamg.ac.at (W.K.)

7 German Climate Computing Centre DKRZ, 20416 Hamburg, Germany; Anders@dkrz.de

8 Department for Climatology, Central Institute of Meteorology and Geodynamics, 1190 Vienna, Austria; Konrad.Andre@zamg.ac.at

9 Field Station for Epidemiology, University of Veterinary Medicine Hannover, 49456 Bakum, Germany; Isabel.Hennig-Pauka@tiho-hannover.de

* Correspondence: gunther.schauberger@vetmeduni.ac.at

Abstract: Economic risks for livestock production are caused by volatile commodities and market conditions, but also by environmental drivers such as increasing uncertainties due to weather anomalies and global warming. These risks impact the gross margin of farmers and can stimulate investment decisions. For confined pig and poultry production, farmers can reduce the environmental impact by implementing specific adaptation measures (AMs) to reduce heat stress. A simulation model driven by meteorological data was used to calculate indoor climate for 1981 to 2017. This dataset was extrapolated for a projection in the year 2030. The heat stress was calculated for a businessas-usual livestock building and for several AMs. For 2030, the expected value of the reduction of the gross margin was calculated by EUR $3.98 \mathrm{a}^{-1}$ per animal place for the business-as-usual scenario. The results show that only energy-saving adaptation measures to reduce the inlet air temperature are appropriate to reduce the economic risk to the level of the year 1980 between EUR $0.03 \mathrm{a}^{-1}$ and EUR $1.02 \mathrm{a}^{-1}$ per animal place. The efficiency of other AMs to reduce heat stress is distinctly lower (between EUR $2.62 \mathrm{a}^{-1}$ and EUR $3.80 \mathrm{a}^{-1}$ per animal place). The results in this study can support the decision making of farmers concerning adaptation management and investments. It can inform agricultural policy design as well as technological development.

Keywords: farm animal; pig; livestock production; global warming; climate change; economic risk assessment; economic impact; resilience; livestock farming; adaptation 


\section{Introduction}

Climate change is a significant threat for livestock production due to drought prone feed production and pasture growth [1-3], an increase in health risks and mortality from heat stress (HS) [4], as well as emergence of new diseases and transmitting vectors [5-10]. In mid-latitudes the majority of pigs and poultry are kept inside confined livestock buildings, which are often perceived as elements of industrial livestock systems [11,12]. The predominant type of confined livestock buildings is characterised by a mechanical ventilation system and high stocking density in insulated buildings. At the global level, more than half of the pig and poultry populations are kept under these husbandry conditions [13]. Consequently, HS inside livestock buildings increased even in a temperate climate of Central Europe in the range between $0.9 \%$ and $6.4 \%$ per year between 1981 and 2017 [14]. This has an impact on the economic risk $(E R)$ for livestock production, which may further increase in the future. The communication of the economic impact of climate change in the context of livestock farming is often addressing the national level. In France and Spain, the extremely hot year 2003 caused additional costs of EUR 100 million each for the intensive livestock sector and a feed deficit in the range of 30\% for Germany, Austria and Spain, about $40 \%$ in Italy and about $60 \%$ in France. In Spain, the mortality of broilers was in the range of 15 to $20 \%$ with a decrease of productivity by 25-30\%. In France, about 4 million broilers died [2]. For fattening pigs, Schauberger et al. [15] determined the loss in gross margin for a 10-year return period in an Austrian case study with EUR 0.27 per year and animal place in 1980 and a 20-fold increase to EUR 5.13 per year and animal place in 2030. These economic losses are caused by an increase in the feed conversion ratio, a lower growth rate, and other productivity traits such as increasing mortality [3,16-19].

Adaptation measures (AMs) have been proven effective to reduce HS in confined livestock buildings [15,20,21]. They can be grouped into measures adapting (1) the ventilation system to modify the thermodynamic properties of the inlet air (air temperature and humidity), (2) the building (e.g., insulation, orientation) [22], (3) the indoor equipment at the animal level to modify the indoor climate on a small scale (e.g., sprinkling and fogging systems, forced ventilation), and (4) the livestock management (e.g., thermotolerant breeds, feeding, design values of the ventilation system) [20].

The scale of the operating figures is beyond everyday experiences of farmers. Neither the reported HS parameters for animals [14] nor macroeconomic figures on a national level can be directly used by farmers to make decisions, which of the available AMs should be selected to reduce the impact of climate change on farm animals. Livestock specific information on the likelihood and severity of future HS and the costs and benefits of AMs support investment decisions in new livestock housing systems and reduce the economic risks of stranded assets in the field of livestock farming. In addition, all future approaches to increase sustainability in animal production systems have to target the alleviation of HS. In addition to animal welfare improvement, possible economic benefits are important arguments for farmers to adopt AMs and thereby manage the economic risks caused by HS.

Due to the stochastic element of the weather, the concept of the weather-related Valueat-Risk (weather-VaR) was applied as a decision tool $[23,24]$. We use the weather-VaR to describe the ER caused by HS on the gross margin of growing-fattening pigs. With this tool, the expected mean value of the reduction of the gross margin caused by global warming can be calculated but also the return period (10 or 20 years), taking into account the stochastic weather behaviour [15].

This paper describes a three-step process. In the first step, the likelihood of HS is calculated using a simulation model for indoor air of a confined livestock building, which is driven by meteorological data. The stochastic behaviour of weather elements is the primary input for the uncertainty from year to year. The reduction of HS by several AMs is calculated in comparison to a business-as-usual pig building as a reference. In a second step, the impact of HS on the gross margin for the fattening pig sector is calculated by the modified impact function of St-Pierre et al. [17]. In the last step, the likelihood of HS and the impact function are combined to determine the likelihood of the $E R$ for the near 
future (i.e., 2030) on the basis of the weather-VaR concept for the reduction of the gross margin per animal place $[15,24]$. The reduction of the ER due to the application of AMs is the relevant output to support farmers' management decisions for the planning of new or the adaptation of existing livestock buildings.

The following questions will be answered by this investigation: (1) which AMs are appropriate to reduce HS and to increase the resilience of livestock buildings against global warming, (2) what is the expectation for the occurrence of HS in the near future by the use of AMs, and (3) what is the expectation for the mean $E R$ and the VaR in the near future.

\section{Materials and Methods}

\subsection{Simulation of the Thermal Climate inside Livestock Buildings}

The likelihood of HS is determined by a simulation model of the indoor climate of a confined livestock building, which is driven by meteorological data, directly measured at the site of investigation, the city of Wels in Upper Austria $\left(48.16^{\circ} \mathrm{N}, 14.07^{\circ} \mathrm{E}\right)$ for the period 1981 to 2017 with a temporal resolution of one hour. This site is located in the $\mathrm{Cfb}$ class, according to the Köppen-Geiger climate classification, i.e., temperate oceanic climate (warm temperature, fully humid, warm summers). In this zone the highest animal density of industrial livestock buildings can be found for Europe, North America and parts of Asia (predominantly China) [20].

The indoor climate of the livestock building was simulated by a steady-state model, which calculates the indoor parameters, air temperature and humidity, and the ventilation flow rate. The thermal environment inside the building depends on the livestock, the thermal properties of the building, the ventilation system, and its control unit. The core of the model is the calculation of the sensible heat balance of a livestock building $[14,25,26]$. The model calculation was performed for a typical building for fattening pigs in Central Europe for 1800 heads, divided into nine sections, with 200 animals each. The model calculations were performed for the entire growing-fattening period, i.e., for a body mass between 30 and $120 \mathrm{~kg}$. The system parameters (livestock, thermal properties of the building and ventilation system) of the livestock building are discussed in detail in [14]. The HS of the business-as-usual system REF was compared afterwards based on the HS index, which is reduced by the application of different AMs.

\subsection{Quantification of Heat Stress}

The temperature-humidity index (THI) was used to quantify the indoor HS for pigs according to $T H I=0.72 T+0.72 T_{W B}+40.6$, where $T_{W B}$ represents the wet-bulb temperature. The THI threshold $X=75$ represents an alert situation of the thermal environment [22]. The intensity of HS, $A_{T H I 75}$, was assessed by the aggregated values larger than $X=75$ and the time course of the THI (i.e., the area under the curve over time). The THI was calculated for the reference system (REF) and the seven modelled AMs to reduce HS. The THI index was further processed as annual sums.

The expected value (mean value) of the THI for the modelled AMs for a certain year $t$, was calculated by a simple linear model, fitted to the logarithmically transformed yearly values $A_{\text {THI75 }}$ by $m_{t}=k t+d$, with the slope $k$ and the intercept $d$. The linear regression was evaluated by the correlation coefficient $r$ and the corresponding $p$-value.

The logarithmically transformed values were detrended by a linear regression according to $\Delta_{t}=m_{t}-\log A_{T H I 75, t}$. The expected occurrence of the HS index is calculated by a normal distribution $\mathrm{N}\left(m_{t}, \sigma^{2}\right)$, using the mean value from the linear regression $m_{t}$ of a certain year $t$ and the variance $\sigma^{2}$ of the detrended values $\Delta_{t}$ [15]. The projection for the near future was performed for the year $t=2030$. This year was selected because the projection is based on the extrapolation of the trend of the meteorological data from the period 1981 to 2017. Therefore, the extrapolation was limited to the short period of 13 years assuming that the trend can be applied to this period without further modifications, e.g., an exponential increase in air temperature more likely beyond this period. 
The likelihood of the occurrence of HS can be quantified by a probability density function, which is defined by the temporal trend (caused by global warming) and a stochastic component. The expected value $m_{2030}$ is determined by the linear trend of the logarithmically transformed annual values of the HS index $A_{T H I 75}$, the stochastic component by the variance $\sigma^{2}$ of the detrended values. We selected a normal distribution $\mathrm{N}\left(m_{2030}, \sigma^{2}\right)$ [15].

The trends of the $\log A_{\text {THI75 }}$ for the modelled AMs were analysed by the signal-to-noise ratio (SNR) and the Mann-Kendall Trend Test. The SNR was calculated using the linear trend $k$ over 37 years and the standard deviation of $\log A_{T H I 75}$. Under the assumption that the $S N R$ is distributed with the standard normal distribution $\mathrm{N}(0 ; 1)$, limits for the $S N R$ and the $p$-values are as follows [27]: low significance $1.645<S N R \leq 1.960(0.05<p \leq 0.10)$, medium significance $1.960<S N R \leq 2.576(0.01<p \leq 0.05)$, and high significance $S N R$ $>2.576(p \leq 0.01)$. The second test for the trend of the HS indices was the rank-based non-parametric Mann-Kendall trend test with the test statistics $\tau$ and a one-sided test for an increasing temporal trend using the $\mathrm{R}$ package trend.

\subsection{Modification of HS inside Pig Buildings by the Use of Adaptation Measures}

For this investigation, two groups of AMs were analysed. The efficacy of the first seven AMs was assessed by a simulation model [21]. The efficacy of the second group of 14 AMs was estimated by a panel of experts using the modelled AMs as a reference [20].

In the first group the following seven AMs were modelled: The first three are energysaving systems which are part of the ventilation system and modify the thermodynamic properties of the inlet air (air temperature and humidity) [22]. Three different energysaving systems were investigated: (1) direct evaporative cooling by cooling pads (CP), (2) an indirect evaporative cooling by the combination of $\mathrm{CP}$ with a regenerative heat exchanger (CPHE) to reduce the humidity load caused by the evaporative cooling, and (3) an earth-air heat exchanger (EAHE), using the ground as heat storage. The fourth AM assumes an inversion of the feeding and resting times by half a day to move the maximum heat release of the animals to night-time with a lower inlet air temperature, INV. Two further AMs modify the internal heat load of the livestock building by a reduction of the stocking density SD to (5) $80 \%$ of the design value (SD80\%) and (6) to $60 \%$ (SD60\%). The last AM (7) affects the design value of the ventilation system by doubling the maximum volume flow rate (VENT) to increase the removal of the sensible heat released by the animals.

An assessment of the estimated efficacy of the following AMs by an expert panel was performed [20]: Geothermal cooling of the inlet air by groundwater (GEO) as one additional air treatment AM; four AMs of building features, orientation of the building (ORIENTATION), green façade/roof sprinkling (ROOF), insulation of the buildings (INSULATION), and shading by plants (SHADE); seven AMs manipulating the environmental conditions at the animal level, increased air velocity (FORCED), sprinkling (SPRINKLING), high pressure fogging (FOGGING), chilled drinking water (WATER), cooled laying area (CONDUCT), radiative cooling (RADIANT), and wallow (WALLOW); and two additional AMs concerning livestock management, feeding strategies (FEED), and adapted breeds (BREED).

\subsection{Economic Impact of HS}

The economic impact assessment is based on the reduction of the gross margin as a function of HS, estimated by the growing-fattening pig model of St-Pierre et al. [17]. The reduction of the gross margin is calculated by three parameters on an annual basis for one animal place: the reduction of body mass at the end of the fattening period $\left(\mathrm{kg} \mathrm{a}^{-1}\right)$ (revenue), the reduction of dry matter intake $\left(\mathrm{kg} \mathrm{a}^{-1}\right)$ (variable costs) and the increase of mortality (\%) (revenue). These three parameters were updated by data for 2020 from the Federal Institute of Agricultural Economics, Rural and Mountain Research (BAB http: / / www.BAB.gv.at/, accessed on 15 December 2021) for feed with EUR $0.25 \mathrm{~kg}^{-1}$, the revenue for a fattening pig with EUR $1.7 \mathrm{~kg}^{-1}$, and the cost of a dead pig $(75 \mathrm{~kg})$ with EUR 100 [15]. The original predictor of the impact function for growing-fattening pigs of St-Pierre et al. [17] is the area under the curve $A_{T H I 75}$ for a THI threshold of $X=72$. By 
the dataset of the HS index using the two THI thresholds, $X=72$ (growing-fattening pigs) and $X=74$ (sows), the impact function was modified for the THI threshold $X=75$ used in this paper.

The economic impact IMP (EUR $\mathrm{a}^{-1}$ ) related to one animal place as a linear function of the HS index $A_{\text {THI75 }}\left(\mathrm{h} \mathrm{a}^{-1}\right.$ ) reads as follows: IMP $=0.0016 A_{\text {THI75 }}$ with $r^{2}=0.9897$ (Figure 1).

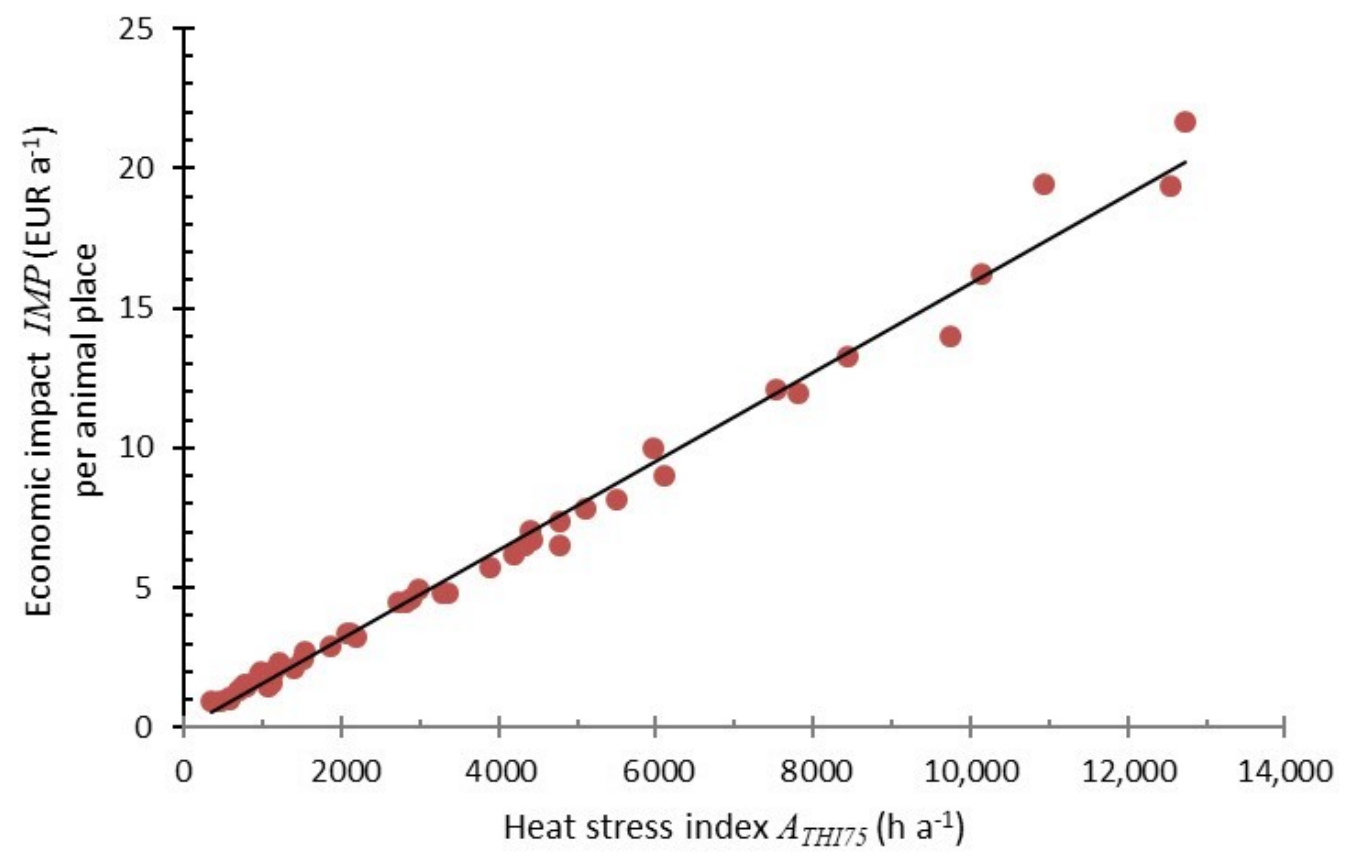

Figure 1. Economic impact IMP (EUR a ${ }^{-1}$ per animal place), described by the reduction of the gross margin per animal place as a linear function of the heat stress index $A_{T H I 75}\left(\mathrm{~h} \mathrm{a}^{-1}\right)$ derived from St-Pierre et al. [17] with $I M P=0.0016 A_{T H I 75}$, reprinted from reference [15].

\section{Results}

\subsection{HS of the Reference Livestock Building (REF) and the Reduction of HS by the Application} of $A M s$

The relationship of HS between the reference livestock building (REF), which is calculated for a business-as-usual management and the modelled AMs, is shown in Figure 2. The lowest performance is reached by a reduction of the livestock density (SD80\% and SD60\%), followed by inverting the activity of the animals to the night-time (INV) and by doubling the maximum volume flow rate (VENT). The distinctly best performance can be expected for energy-saving systems, which cool the inlet air (CPHE, CP, and EAHE). All investigated AMs show a lower HS inside the livestock building compared to the REF building.

The resilience of the confined livestock system against HS was assessed by the relationship between the HS indices $A_{\text {THI75 }}$ calculated from the outdoor parameters on the one hand, and the indoor climate for the reference system (REF) and buildings equipped with one of the seven modelled AMs. The linear regression of the outdoor situation on the indoor situation is shown in Figure 3. If the HS indices are above the line of identity, then the resilience of the indoor climate is lower compared to the outdoor situation (REF, SD80\%, $\mathrm{SD} 60 \%$, INV, and VENT). Only the AMs, which reduce the inlet air temperature, show a higher resilience compared to the outside situation. For these AMs, the indoor and the outdoor situation is decoupled to a large extent. The lower resilience results in a higher HS indoors compared to the outdoor situation (above the line of identity between HS outdoor and indoor). 


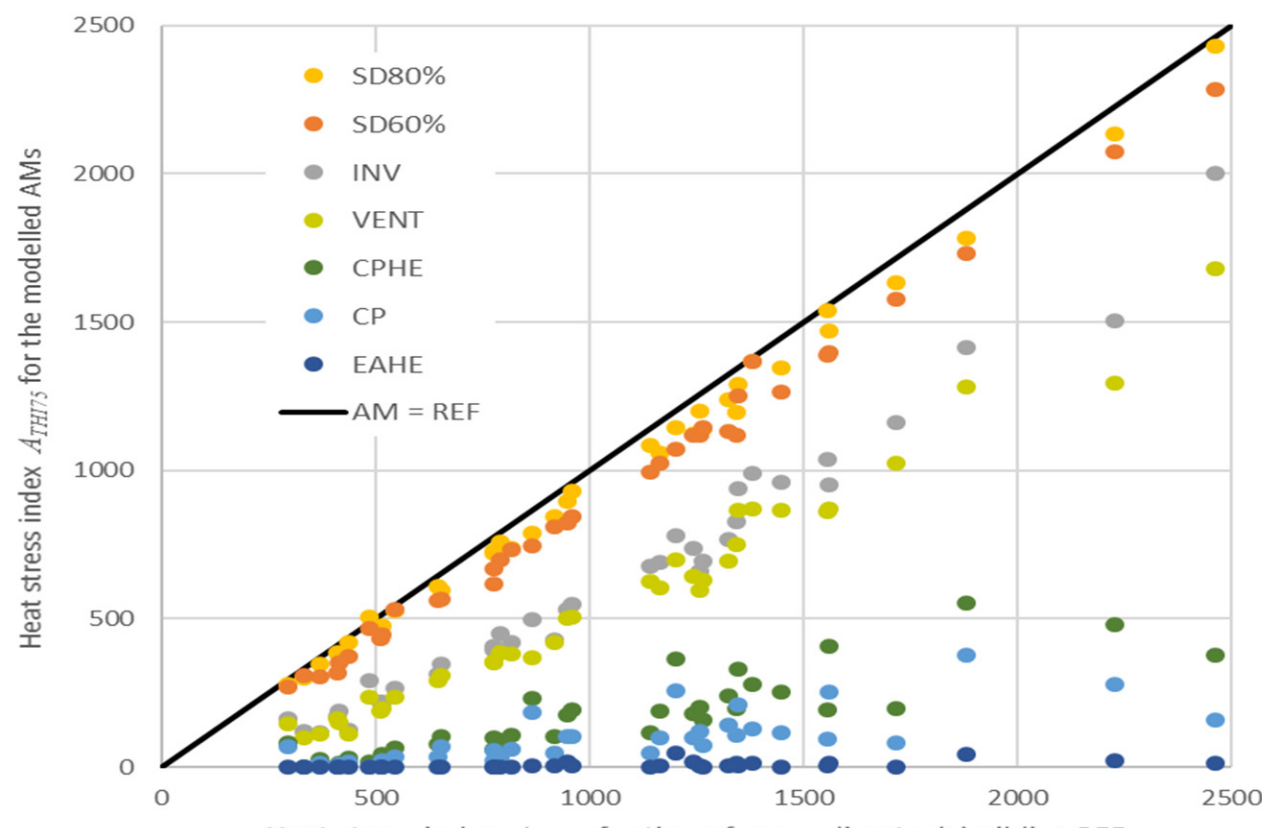

Figure 2. Relationship of the simulated heat stress index $A_{T H I 75}$ (area under the curve and a THI threshold of $X=75$ ) for the seven modelled AMs as a function of a reference livestock building (REF), reprinted from reference [20]. Direct evaporative cooling by cooling pads (CP), indirect evaporative cooling (CPHE), earth-air heat exchanger (EAHE), inversion of the feeding and resting times (INV), reduction of the stocking density to $80 \%$ of the design value (SD80\%), and to $60 \%$ (SD60\%), doubling the maximum volume flow rate (VENT).

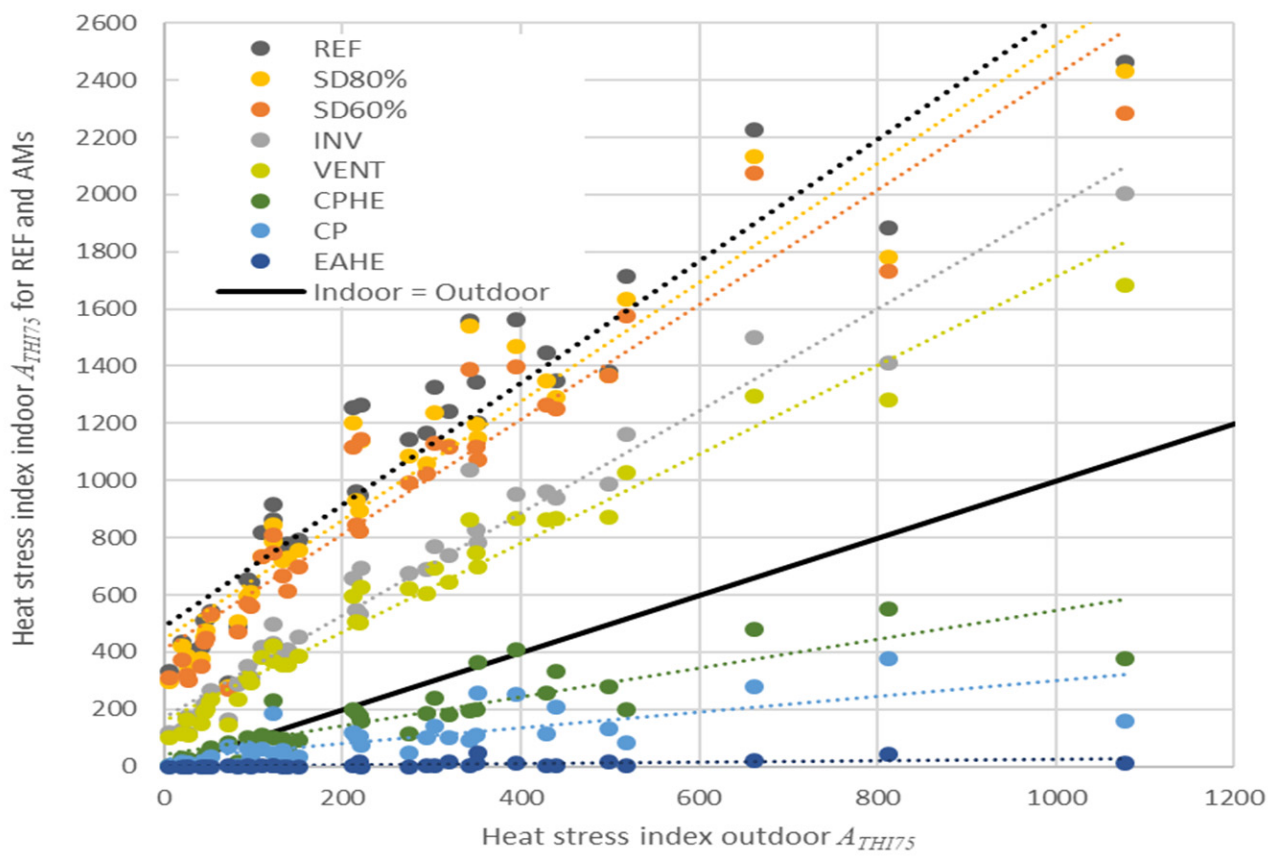

Figure 3. Relationship of the outdoor HS index $A_{T H I 75}$ (area under the curve and a THI threshold of $X=75$ ) on the modelled HS index $A_{T H I 75}$ for the reference building (REF) and the seven AMs. For REF and each AM, a linear regression shows the impact of the outdoor heat stress on the indoor heat stress. Direct evaporative cooling by cooling pads (CP), indirect evaporative cooling (CPHE), earth-air heat exchanger (EAHE), inversion of the feeding and resting times (INV), reduction of the stocking density to $80 \%$ of the design value (SD80\%), and to $60 \%$ (SD60\%), doubling the maximum volume flow rate (VENT). 
The temporal trend between 1981 and 2017 of the HS index $A_{\text {THI75 }}$ was analysed by a linear model (Table 1). The logarithmically transformed HS parameter shows a highly significant correlation $(p<0.01)$ for the reference building (REF) and for the seven modelled AMs. The temporal trend was tested by the signal-to-noise ratio SNR and the MannKendall Trend Test (Table 2). Both tests show a significant trend, at least with $p<0.05$. The higher the efficacy of the AMs, the lower the statistical significance.

Table 1. Temporal trend of the heat stress index $A_{T H I 75}$ (area under the curve and a THI threshold of $X=75$ ) for the reference livestock building (REF) and the seven modelled AMs by the use of the linear regression $m_{t}=k t+d$, calculated by the logarithmically transformed heat stress index log $A_{\text {THI75, }}$ over time $t$ with the slope $k$, the intercept $d$, the correlation coefficient $r$, and the $p$-value. Direct evaporative cooling by cooling pads (CP), indirect evaporative cooling (CPHE), earth-air heat exchanger (EAHE), inversion of the feeding and resting times (INV), reduction of the stocking density to $80 \%$ of the design value (SD80\%), and to 60\% (SD60\%), doubling the maximum volume flow rate (VENT).

\begin{tabular}{ccccc}
\hline \multirow{2}{*}{ Model Calculations } & \multicolumn{3}{c}{ Linear Regression of the Temporal Trend } \\
\cline { 2 - 5 } & Trend $\boldsymbol{k}$ & Intercept $\boldsymbol{d}$ & Corr. $\boldsymbol{r}$ & $\boldsymbol{p}$ \\
\hline REF & 0.0144 & -25.738 & 0.6430 & $<0.001$ \\
SD80\% & 0.0146 & -26.272 & 0.6464 & $<0.001$ \\
SD60\% & 0.0142 & -25.556 & 0.6192 & $<0.001$ \\
INV & 0.0181 & -33.520 & 0.6000 & $<0.001$ \\
VENT & 0.0187 & -34.816 & 0.6196 & $<0.001$ \\
CPHE & 0.0260 & -49.974 & 0.4721 & 0.003 \\
CP & 0.0262 & -50.619 & 0.4269 & 0.008 \\
EAHE & 0.0363 & -72.530 & 0.4277 & 0.008 \\
\hline
\end{tabular}

Table 2. Statistical analysis of the temporal trend of the heat stress index $A_{T H I 75}$ (area under the curve and a THI threshold of $X=75$ ) for the reference livestock building (REF) and the seven modelled AMs by the signal-to-noise ratio SNR and the Mann-Kendall Trend Test with the test statistics $\tau$ and the corresponding $p$-values. Direct evaporative cooling by cooling pads (CP), indirect evaporative cooling (CPHE), earth-air heat exchanger (EAHE), inversion of the feeding and resting times (INV), reduction of the stocking density to $80 \%$ of the design value (SD80\%), and to $60 \%$ (SD60\%), doubling the maximum volume flow rate (VENT).

\begin{tabular}{ccccc}
\hline Model Calculations & \multicolumn{2}{c}{ Signal-to-Noise Ratio } & \multicolumn{2}{c}{ Mann-Kendall Trend Test } \\
\hline & SNR & $\boldsymbol{p}$ & $\boldsymbol{\tau}$ & $\boldsymbol{p}$ \\
\hline REF & 2.198 & 0.018 & 0.4414 & $<0.001$ \\
SD80\% & 2.210 & 0.017 & 0.4625 & $<0.001$ \\
SD60\% & 2.117 & 0.022 & 0.4414 & $<0.001$ \\
INV & 2.051 & 0.026 & 0.4162 & $<0.001$ \\
VENT & 2.118 & 0.022 & 0.4252 & $<0.001$ \\
CPHE & 1.614 & 0.065 & 0.3784 & 0.001 \\
CP & 1.459 & 0.087 & 0.3411 & 0.002 \\
EAHE & 1.462 & 0.087 & 0.3124 & 0.004 \\
\hline
\end{tabular}

\subsection{Consequence of Global Warming on the Likelihood of Heat Stress}

The parsimonious model, using the linear regression of the HS index $A_{T H I 75}$, was used to determine the likelihood of its occurrence in a certain year $t$. In Figure 4 the likelihood for the near future $(t=2030)$ is shown by the probability density function (PDF). The likelihood for the reference building (REF) for the year 1980 is added to show the impact of global warming on the occurrence of HS. 


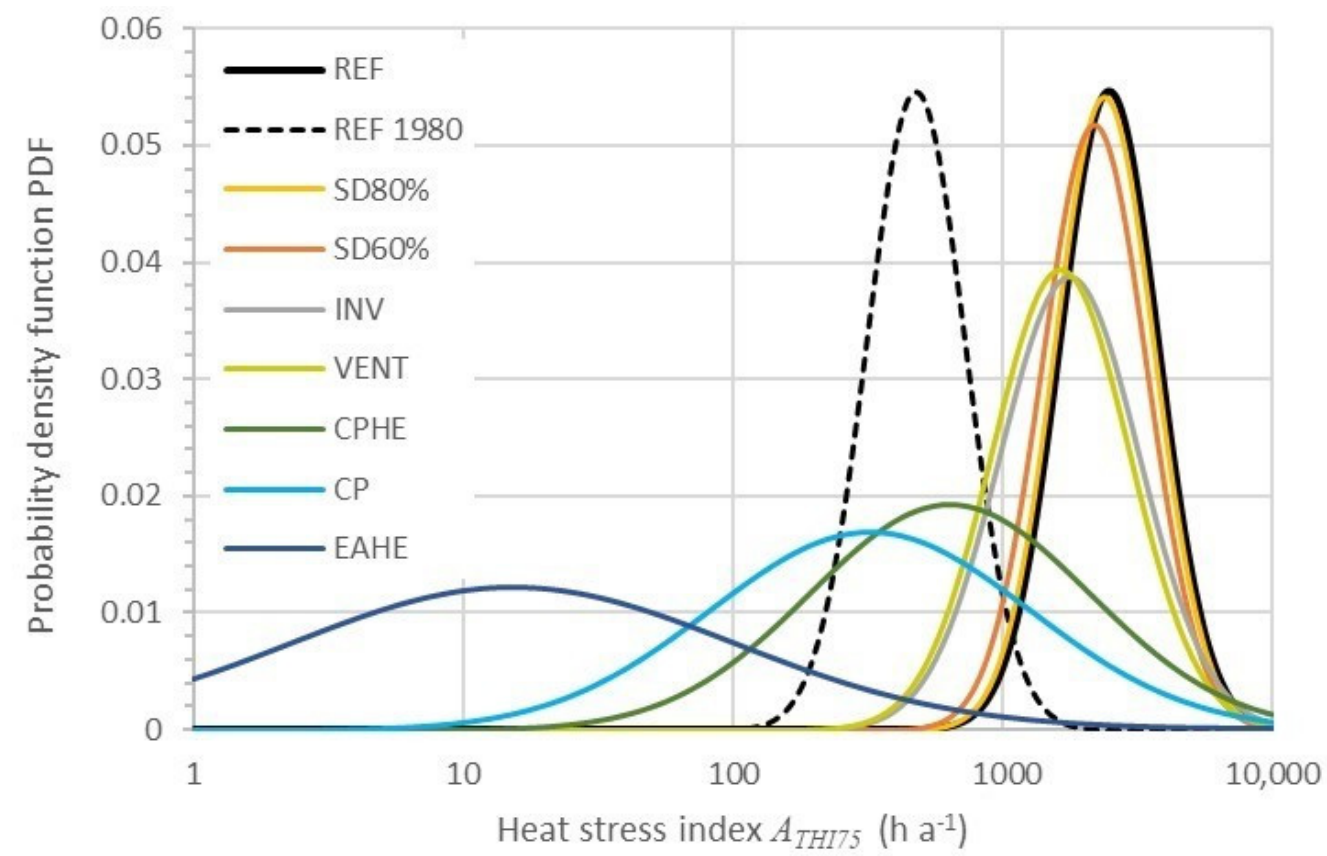

Figure 4. Likelihood for the occurrence of the HS index $A_{T H I 75}$ (area under the curve and a THI threshold of $X=75$ ) for the reference livestock building (REF) and the seven modelled AMs for 2030. The likelihood for the reference building (REF) for 1980 is shown in comparison. Direct evaporative cooling by cooling pads (CP), indirect evaporative cooling (CPHE), earth-air heat exchanger (EAHE), inversion of the feeding and resting times (INV), reduction of the stocking density to $80 \%$ of the design value (SD80\%), and to 60\% (SD60\%), doubling the maximum volume flow rate (VENT).

The efficacy of the AMs to alleviate heat stress in the near future can be seen from the shift of the PDFs towards the left. The unabated REF situation shows the highest probability for the occurrence of heat stress. The three AMs, which reduce the inlet air temperature (CPHE, $\mathrm{CP}$, and EAHE), can achieve even lower heat stress levels compared to the historical situation of 1980. All other AMs are far less effective.

\subsection{Economic Risk for Pig Farms Due to Global Warming}

The economic risk, $E R$, due to a global warming trend for the pig fattening sector, was assessed by the product of the likelihood of HS (Figure 4) and the economic impact function IMP, which describes the expected reduction of the gross margin as a function of the HS index $A_{T H I 75}$, shown in Figure 1. The probability density function (PDF) of the $E R$ is presented in Figure 5. The expected value of the $E R$ for the near future, i.e., 2030, is shown by the maximum of the PDF. The shift of the mean value to higher values is caused by the global warming trend, whereas the uncertainty (width of the PDF) is caused by the stochastic character of the meteorological data. This is represented by the width of the PDF in Figure 5. All AMs reduce the ER but the three AMs which reduce the inlet air temperature are showing by far the best performance. The weather-VaR is represented by the 10 a return period (90th percentile) or the 20 a return period (95th percentile). These two parameters can be read directly from the cumulative distribution function CDF of the $E R$, shown for the seven AMs and the REF in Figure 6. The CDFs for the air treatment AMs are located below a gross margin reduction of EUR $1.0 \mathrm{a}^{-1}$ per animal place, in the same range or even better as the reference building (REF) in 1980. The detailed data for the expected value and the two return periods are summarised in Table 3. 


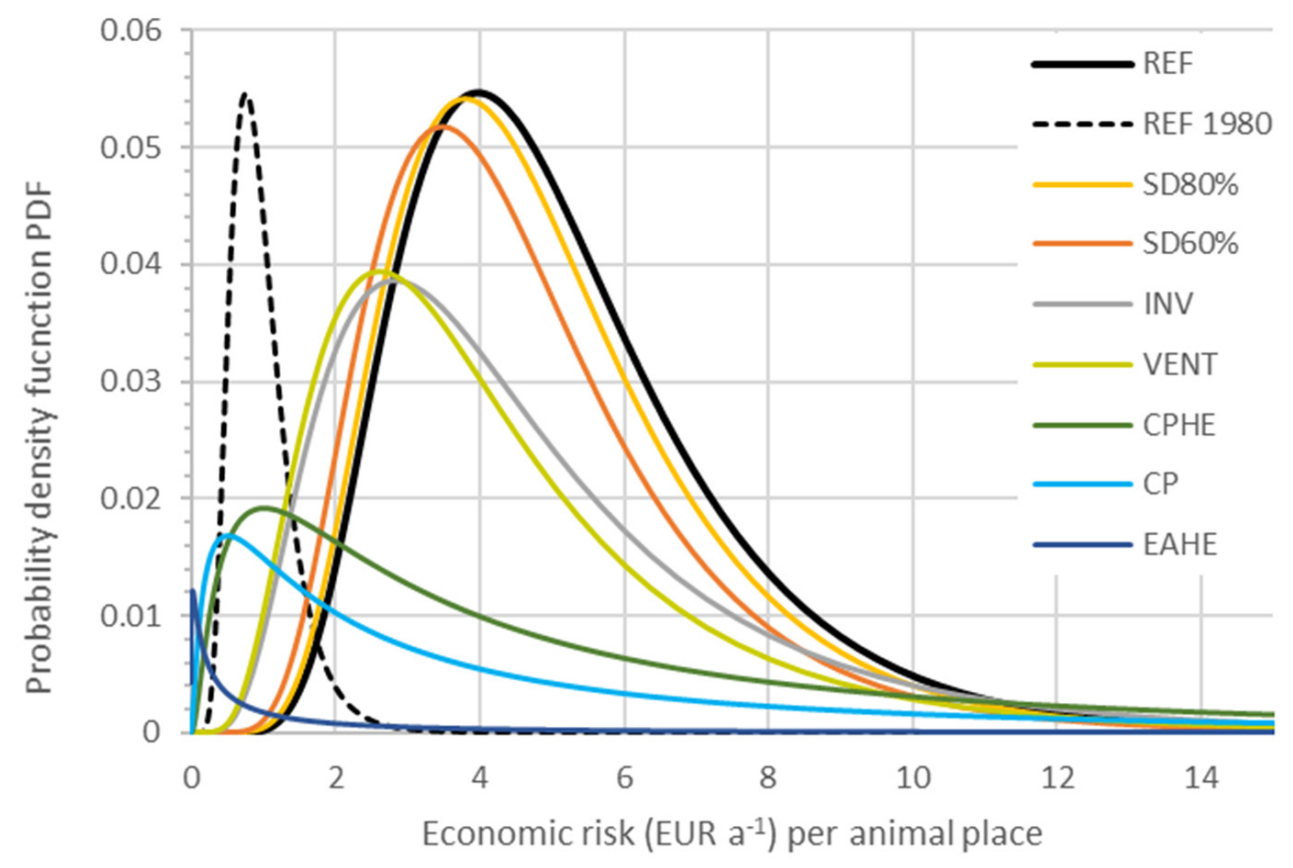

Figure 5. Likelihood of the economic risk $E R\left(E U R \mathrm{a}^{-1}\right)$ per animal place for the reference livestock building (REF) and the seven modelled AMs for 2030. The likelihood for the reference building (REF) for 1980 is shown in comparison. Direct evaporative cooling by cooling pads (CP), indirect evaporative cooling (CPHE), earth-air heat exchanger (EAHE), inversion of the feeding and resting times (INV), reduction of the stocking density to $80 \%$ of the design value (SD80\%), and to $60 \%$ (SD60\%), doubling the maximum volume flow rate (VENT).

In addition to the seven modelled AMs (e.g., Table 2), an assessment of the estimated efficacy of the fourteen additional AMs by an expert panel was included [20] as mentioned above.

For these AMs, the reduction factor was estimated based on the experience from experts in the field of agricultural engineering and veterinary medicine. Experts were asked for the expected minimum and maximum values for heat stress reduction by a single AM compared to a reference situation. These values led to a minimum and maximum reduction factor $\mathrm{RF}_{\mathrm{AM}}$. The HS index of an estimated AM $A_{T H I 75, A M}$ is then calculated by multiplying the estimated reduction factor $R F_{A M}$ and the HS for the reference building (REF) $A_{T H I 75, R E F}$ according to $A_{T H I 75, A M}=R F_{A M} A_{T H I 75, R E F}$. The ER was calculated by a multiplication of $A_{T H I 75, A M}$ with the economic impact function IMP (Figure 1). The results for the modelled AMs and the estimated AMs are summarised in Table 4, showing the mean value of the $E R$ and the confidence interval for the modelled AMs and the range (maximum-minimum) of ER for those AMs, which were evaluated by the expert panel.

The ER are lowest for the energy-saving air treatment systems and highest for building features. For these features, the reduction factors were less than $8 \%$. The AMs, which are working on an animal level, modifying the microenvironment of the animals, show a wide variety of efficacy. For all AMs, the presented reduction factors and the corresponding ER assessment are only valid for the application as single AM. 


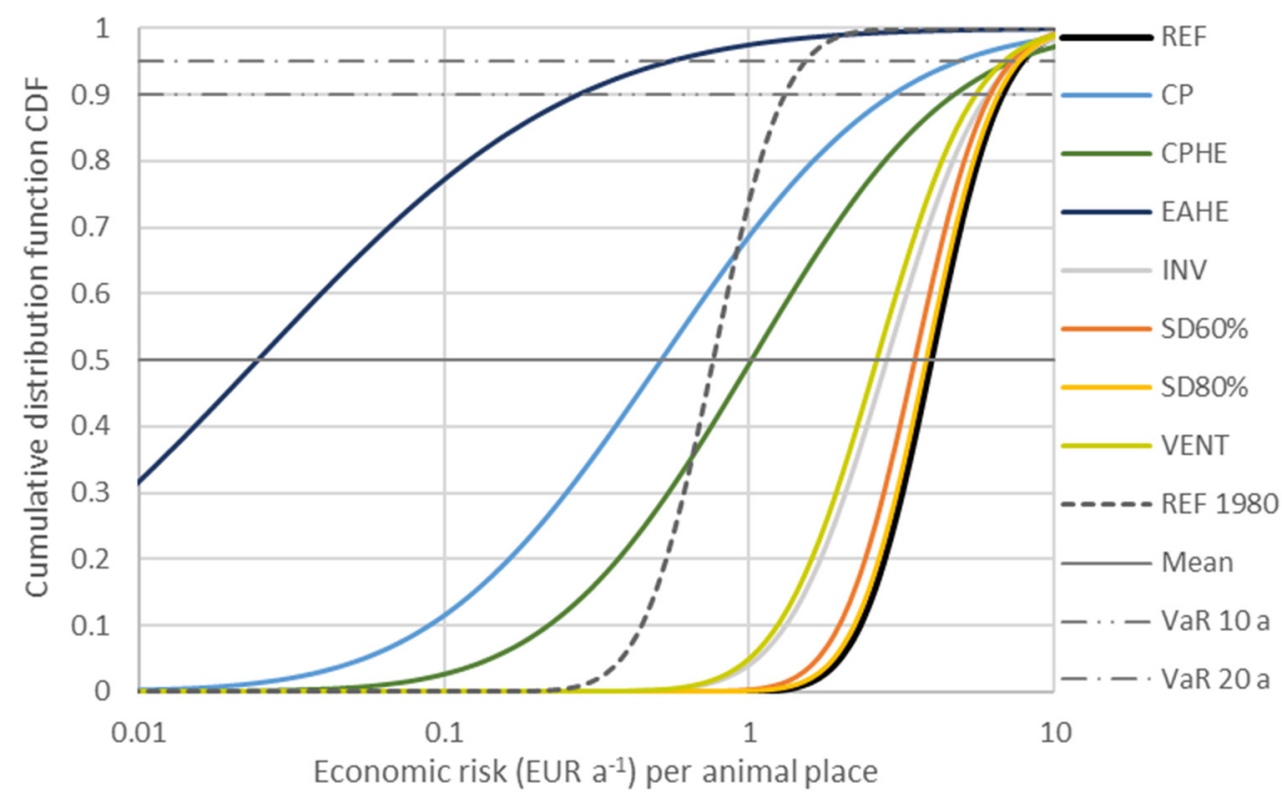

Figure 6. Cumulative distribution function CDF of the economic risk $E R\left(E U R \mathrm{a}^{-1}\right)$ per animal place for the reference livestock building (REF) and the seven modelled AMs for 2030. The likelihood for the reference building (REF) for 1980 is shown in comparison. The expected economic risk (mean value) and weather-VaR for a 10 a and 20 a return period (90- and 95-percentile) is highlighted. For the business-as-usual REF the expected value for the ER is EUR $4.98 \mathrm{a}^{-1}$ per animal place. The weather-VaR reaches EUR $6.80 \mathrm{a}^{-1}$ per animal place and EUR $7.90 \mathrm{a}^{-1}$ per animal place for a $10 \mathrm{a}$ and a 20 a return period, respectively. Direct evaporative cooling by cooling pads $(\mathrm{CP})$, indirect evaporative cooling (CPHE), earth-air heat exchanger (EAHE), inversion of the feeding and resting times (INV), reduction of the stocking density to $80 \%$ of the design value (SD80\%), and to $60 \%$ $(\mathrm{SD} 60 \%)$, doubling the maximum volume flow rate (VENT).

Table 3. Statistics of the economic risk $E R$ by the reduction of the gross margin (EUR $\mathrm{a}^{-1}$ ) per animal place for the year 2030 by the expected values of the economic risk (mean) and the weather-VaR for a return period of 10 a and 20 a, respectively. Direct evaporative cooling by cooling pads (CP), indirect evaporative cooling (CPHE), earth-air heat exchanger (EAHE), inversion of the feeding and resting times (INV), reduction of the stocking density to $80 \%$ of the design value (SD80\%), and to $60 \%$ (SD60\%), doubling the maximum volume flow rate (VENT).

\begin{tabular}{cccc}
\hline & \multicolumn{3}{c}{ Reduction of the Gross Margin (EUR a $\left.{ }^{-1}\right)$ per Animal Place } \\
\cline { 2 - 4 } & Mean & \multicolumn{2}{c}{ Weather-VaR } \\
\cline { 2 - 4 } & & $\begin{array}{c}\text { 90-Percentile } \\
(\mathbf{1 0} \text { a Return Period) }\end{array}$ & $\begin{array}{c}\text { 95-Percentile } \\
\text { (20 a Return Period) }\end{array}$ \\
\cline { 2 - 4 } REF & 3.98 & 6.81 & 7.94 \\
SD80\% & 3.80 & 6.55 & 7.64 \\
SD60\% & 3.49 & 6.16 & 7.24 \\
INV & 2.83 & 6.05 & 7.51 \\
VENT & 2.62 & 5.53 & 6.84 \\
CPHE & 1.02 & 4.69 & 7.24 \\
CP & 0.52 & 2.96 & 4.85 \\
EAHE & 0.03 & 0.28 & 0.55 \\
REF 1980 & 0.76 & 1.31 & 1.52 \\
\hline
\end{tabular}


Table 4. Overview of the investigated adaptation measures, AMs, the method of the efficacy assessment (model result $\mathrm{M}$ /expert estimate $\mathrm{E}$ ), the efficacy (\%) in reduction of the heat stress parameter

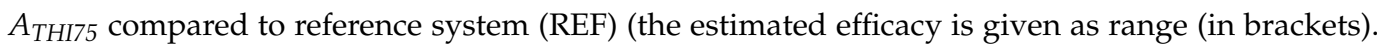
Reprinted from reference [15]. The projection of the economic risk is given by the expected value (mean value) and the confidence interval (upper limit, lower limit) or by the estimated range of the efficacy (maximum, minimum). Modeled AMs: Direct evaporative cooling by cooling pads (CP), indirect evaporative cooling (CPHE), earth-air heat exchanger (EAHE), inversion of the feeding and resting times (INV), reduction of the stocking density to $80 \%$ of the design value (SD80\%), and to $60 \%$ $(\mathrm{SD} 60 \%)$, doubling the maximum volume flow rate (VENT). Expert estimate: Geothermal cooling (GEO), orientation of the building (ORIENTATION), green façade/roof sprinkling (ROOF), insulation of the buildings (INSULATION), and shading by plants (SHADE), increased air velocity (FORCED), sprinkling (SPRINKLING), high pressure fogging (FOGGING), chilled drinking water (WATER), cooled laying area (CONDUCT), radiative cooling (RADIANT), and wallow (WALLOW), feeding strategies (FEED), adapted breeds (BREED).

\begin{tabular}{|c|c|c|c|}
\hline Adaptation Measure & Method & $\begin{array}{c}\text { Efficacy }(\%) \text { in Reduction of } \\
\text { the Heat Stress Index } A_{T H I 75} \\
\text { Compared to Reference } \\
\text { System (REF) }\end{array}$ & $\begin{array}{c}\text { Projection of the Economic } \\
\text { Risk for } 2030\left(E_{R a^{-1}}\right) \text { per } \\
\text { Animal Place }\end{array}$ \\
\hline REFERENCE SYSTEM (REF) & M & & $3.98[2.61 ; 6.05]$ \\
\hline \multicolumn{4}{|l|}{ AIR TREATMENT } \\
\hline Cooling pads $(\mathrm{CP})$ & M & 92 & $0.52[0.13 ; 2.02]$ \\
\hline Cooling pads plus heat exchanger (CPHE) & M & 86 & $1.02[0.31 ; 3.35]$ \\
\hline Earth-air heat exchanger (EAHE) & M & 99 & $0.03[0.01 ; 0.16]$ \\
\hline Heat exchanger by ground water (GEO) & $\mathrm{E}$ & $(82-97)$ & $(0.12-0.72)$ \\
\hline \multicolumn{4}{|l|}{ BUILDING } \\
\hline Orientation (ORIENTATION) & $\mathrm{E}$ & $(4-7)$ & $(3.66-3.82)$ \\
\hline Green façade/roof sprinkling (ROOF) & $\mathrm{E}$ & $(3-6)$ & $(3.74-3.86)$ \\
\hline Insulation of the buildings (INSULATION) & $\mathrm{E}$ & $(4-8)$ & $(3.66-3.82)$ \\
\hline Shading by plants (SHADE) & $\mathrm{E}$ & $(3-8)$ & $(3.66-3.86)$ \\
\hline \multicolumn{4}{|l|}{ ANIMAL LEVEL } \\
\hline Increased air velocity (FORCED) & $\mathrm{E}$ & $(10-24)$ & $(3.02-3.58)$ \\
\hline Sprinkling (SPRINKLING) & $\mathrm{E}$ & $(22-44)$ & $(2.23-3.1)$ \\
\hline Fogging (FOGGING) & $\mathrm{E}$ & $(42-62)$ & $(1.51-2.31)$ \\
\hline Cooled drinking water (WATER) & $\mathrm{E}$ & $(5-11)$ & $(3.54-3.78)$ \\
\hline Cooled lying area (CONDUCT) & $\mathrm{E}$ & $(20-40)$ & $(2.39-3.18)$ \\
\hline Radiative cooling (RADIANT) & $\mathrm{E}$ & $(10-28)$ & $(2.86-3.58)$ \\
\hline Wallow (WALLOW) & $\mathrm{E}$ & $(23-42)$ & $(2.31-3.06)$ \\
\hline \multicolumn{4}{|l|}{ MANAGEMENT } \\
\hline Stocking density (SD80\%) & M & 6 & $3.80[2.49 ; 5.81]$ \\
\hline Stocking density (SD60\%) & M & 11 & $3.49[2.24 ; 5.44]$ \\
\hline Inversion of activity/resting pattern (INV) & M & 44 & $2.83[1.56 ; 5.12]$ \\
\hline Maximum ventilation rate (VENT) & M & 51 & $2.62[1.46 ; 4.69]$ \\
\hline Adapted breeds (BREEDS) & $\mathrm{E}$ & $(13-30)$ & $(2.78-3.46)$ \\
\hline Dietary and feeding strategy (FEED) & $\mathrm{E}$ & $(20-30)$ & $(2.78-3.18)$ \\
\hline
\end{tabular}




\section{Discussion}

Global warming is strongly influencing Central Europe. This is not only recognizable in the annual values but also in seasonal patterns of core climate indicators. The increasing frequency of hot days and heatwaves in recent decades due to global warming has increased the likelihood for situations that cause HS [28-33]. The prediction of HS in the near future due to global warming and the uncertainty caused by the stochastic behaviour of the meteorological data index can be quantified by a probability density function [33], showing an increasing threat for confined livestock farms [15]. For a Central European case study [15], the simulation of the indoor climate for fattening pigs shows a distinct increase for several HS parameters. For example, the frequency of the exceedance of an indoor temperature threshold of $25{ }^{\circ} \mathrm{C}$ increased between 1989 and 2020 from $7.1 \%$ to $10.5 \%$. For the THI threshold of $X=75$, the frequency more than doubled from $2.8 \%$ in 1980 to $6.3 \%$ in 2020. Schauberger et al. [21] used the HS index $A_{T H I 75}$ (area under the curve A and a THI threshold of 75), which increased from 449 in 1980 to 1666 in 2020, by $271 \%$. Schauberger et al. [15] extended this analysis by a short-range projection for 2030 extrapolating the linear trend over 37 years. Here, the linear trend for a reference livestock building and a number of distinct AMs was calculated using the logarithmically transformed HS index $A_{T H I 75}$. The extrapolation of the trend can be expected as a robust prediction [34]. The trend projections for 2030 have the advantage that not only the expected value (mean value) of the HS index $A_{T H I 75}$ was determined, but also the uncertainty under the assumption of a log-normal distribution. The assumption of linear trends holds for the short-range period in this study but may lose ground for long-term assessments. The trends of temperature extremes accelerated during the last 40 years. The greatest changes were noted for the summer season in Central and Eastern Europe. The trends of temperature extreme events for Europe show that the assumption of a linear trend can be seen as a conservative prediction [35].

Sutton [36] emphasises that assessment and communication of risk merits greater attention. Furthermore, climate change adaptation has become mainstream in agricultural policy agendas. This means that climate change should be framed as a problem of risk assessment and risk management. Therefore, the likelihood of HS was multiplied by an impact function to quantify the risk by HS. This approach was applied for fattening pigs, using the reduction of the gross margin as impact function to quantify the $E R$. The impact function IMP (Figure 1) describes the relationship between the gross margin reduction for one animal place and the HS index $A_{T H I 75}$ [17], which has been adapted to the case study situation and the reference year 2020 [15]. For a business-as-usual livestock building REF, the mean reduction of the gross margin grew from EUR $0.08 \mathrm{a}^{-1}$ to EUR $1.57 \mathrm{a}^{-1}$ per animal place for the period from 1980 to 2020. Taking into account the likelihood of the occurrence of HS, ER was determined for a return period of 20 years with EUR $0.38 \mathrm{a}^{-1}$ and EUR $7.18 \mathrm{a}^{-1}$ per animal place for 1980 and 2030, respectively [15].

This temporal trend shows that, especially for new buildings with an operating period of several decades, there is an urgent need to consider the implementation of AMs to tackle the HS challenge. Therefore, we investigated AMs with a wide variety of efficacy to reduce HS. Data are based on an expert survey of AMs that resulted in HS reduction factors [20], as well as on a simulation of seven AMs [21]. The best performance can be expected for systems that cool the inlet air (CP, CPHE, GEO, and EAHE) with the highest reduction factor for EAHE and GEO [22]. The lowest performance can be expected for measures concerning the features of the building (e.g., ORIENTATION). The efficacy of AMs at animal level (e.g., SPRINKLING, FOGGING) and concerning livestock management (e.g., reduction of stocking density, SD80\% and SD60\%) show a medium performance with remarkable variability. In addition to the reduction factor as a quantitative measure of the AM efficacy compared to a reference building, the improvement of the resilience by the application of the AMs was also investigated. The reference building (REF) shows a lower resilience for global warming compared to the outside situation [14]. In comparison to the situation indoor of the reference building (REF), all modelled AMs show a greater resilience 
(Figure 2). The model calculations also showed that the resilience for those AMs, which cool the inlet air, is even higher in relation to the outside situation (Figure 3). This decoupling of some modelled AMs from outside weather conditions was proven by a higher statistical uncertainty ( $p$-value) of the temporal trend (Table 2).

The economic risk $(E R)$ for a reduction of the gross margin shows a similar behaviour (Figure 5). For CP and EAHE, the mean value of the ER is lower compared to the risk of REF for 1980. This means that, by using these AMs, the impact of global warming can be largely eliminated for the short-range period until 2030. Whether this holds for long range periods with stronger climate change signals needs further investigation. The CPHE shows a slightly higher ER. For the two management related AMs, VENT (doubling of the ventilation rate) and INV (inverting of the resting and activity period), a better performance with a lower ER can be expected compared to a reduction of the stocking density (SD80\% and SD60\%). Using the concept of weather-VaR, not only the expected value (mean value) is taken into account but also the uncertainty by the 90 th percentile (10 a return period) and 95th percentile (20 a return period). For these values, the improvement by the use of AMs is not very high with the anticipated result, that the AMs as part of the ventilation system (cooling the inlet air) show the best performance.

The reduction of the ER with AMs is likely accompanied with additional operating costs including farm labour demand. Furthermore, investment costs have to be taken into account as well, which are typically evaluated by farmers in relation to the profitability of the farm operating with a status-quo reference building. Operating and investment costs lie in a wide interval, depending on the farm size (economies of scale), labour cost or input and output markets (e.g., prices for feed, piglets, and meat) (Germany [37], EU: production costs [38,39], Austria: Federal Institute of Agricultural Economics AWI www.awi.bmnt. gv.at (accessed on 15 December 2021); US: investment costs [40] and variable costs [17], Belgium [41]). The operating costs of AMs are determined by electricity demand (e.g., water pumps for FOGGING, SPRINKLING, CONDUCT, RADIANT; pressure drop for EAHR, CP, CPHE, GEO, FORCED, VENT), water demand for all AMs which used adiabatic cooling by evaporation, and labour costs for maintenance and service. Some of these cost components allow for synergies with climate change mitigation, such as photovoltaic investments on farm buildings, which have become mainstream for energy intensive livestock farms in some regions. The decision on whether a certain AM is economically beneficial can be appraised by a net present value calculation [18]. Decisive parameters typically are the assumed discount rate and future gross margins. Here we assume that gross margins are stable over time. Declining gross margins and a large discount rate would reduce the ER estimates of AMs and vice versa. Hence, sensitivity analysis could be a useful extension to increase the value of our results for farm decision makers. Decisions on AMs as presented in this study either fall into the range of incremental or systemic adaptations. Mitter et al. [42] highlight the long-term time horizon of both the decision making towards systemic adaptations and the duration of the invested fixed farm capital. It is another argument in favour of support for long-term decision making. The ER is calculated as a sum of the following three parameters: the reduction of body mass at the end of the fattening period $\left(\mathrm{kg} \mathrm{a}^{-1}\right)$ (revenue), the reduction of dry matter intake $\left(\mathrm{kg} \mathrm{a}^{-1}\right)$ (variable costs) and the increase of mortality (\%) (revenue). A separated consideration is not possible as it was performed for cattle in a global study by a separation of mortality, fertility and the production level [43]. The result of this study shows a similar trend between 2000 and 2019 as we found in our study.

The profitability is one aspect with typically high priority for farmers. However, the application of AMs multiplies positive and negative effects. For example, impacts on the welfare of animals become increasingly important for the European society. Several diseases are related to HS as a disturbance of the gut microbiome [44], an impacted intestinal barrier ("leaky gut") and high endotoxin concentrations in the blood [45], which might lead to local inflammations [46]. The improvement of the thermal environment and the air quality is a major aspect to ensure the five freedoms for animals and the concept of 
"life worth living" [47]. Therefore, reduced stocking densities, i.e., two of the modelled AMs, can serve two pressing societal needs, although with limited effectiveness on HS. A potential challenge for the effectiveness of some of the analysed AMs could be recent trends towards outdoor ranges of confined livestock buildings, which are reasonable investment options for farmers today. Results on the outdoor heat stress index in this study support such decisions. Water availability under heat stress conditions is a further critical issue to be addressed in the future. Swine have a higher requirement for water with increasing temperatures and additional water is needed for several AMs [48,49]. Due to the fact that water is a limited resource in many regions, water saving technologies are urgently needed [50]. The described AMs have to be assessed for their water saving potential in future studies. Fernandes et al. [51] reviewed costs and benefits for improving farm animal welfare, highlighting that many improvements are difficult to evaluate from a purely economic perspective.

Several environmental side effects are known for some of the investigated AMs. For AMs with a heat exchanger (CPHE, GEO) or a heating system that uses the inlet air below ground (EAHE), the ventilation rate can be increased during wintertime, which increases the air quality as well. This can be quantified by the indoor $\mathrm{CO}_{2}$ concentration. For days with a high diurnal variation of the outdoor temperature, the cooling and/or heating of the inlet air can dampen this variation. Indoor air temperature has an effect on the release of ammonia, odorous substances and dust [52-54]. It can be expected that the application of AMs to reduce HS will also reduce these emissions. Ammonia is an important precursor of fine particulate formation in the atmosphere [55-57] and the related costs [58,59]. The reduction of the ammonia emission is a relevant benefit; as for Europe, about $94 \%$ of ammonia emissions are related to agriculture [60]. Livestock husbandry accounts for about 30 to $40 \%$, besides manure storage and application and the use of fertilizers [61]. For Austria, a reduction of the ammonia emissions by about $26 \%$ has to be achieved on the basis of the national inventory of 2020 to implement the directives of the EU [62]. Environmental odour and the related annoyance is one of the most relevant pollutants, causing complaints in the vicinity of livestock buildings [63], but the impact of global warming on odour emissions and the related protection distances to avoid annoyance has no major effect [64].

A drawback of the investigation presented here is the fact that only one single AM was simulated [65]. The effects from a combination of several AMs cannot be assessed on the basis of these data. The overall efficacy of a combination of AMs could be calculated by an additive or multiplicative operation, and the entire efficacy could show an augmentation or diminution by the combined use of AMs. The simulation of several AMs would be helpful to optimise the design values of such systems. Many reasonable combinations could be determined. All building AMs and some management AMs (e.g., INV, VENT, BREEDS, and FEED) could be combined with the air treatment AMs or the animal level AMs, but also building AMs and management AMs could be useful combinations with lower investment costs. On the other hand, the combination of the air treatment AMs and the animal level AMs does not seem to be useful.

\section{Conclusions}

The communication regarding climate change in the context of livestock farming is often related to economic losses on a national level. The scale of these figures is beyond the everyday experience of farmers. Neither give the reported HS parameters for animals a conclusive picture, nor can the macroeconomic figures on a national level be used directly by farmers to make decisions, which of the available AMs should be selected to reduce the impact of climate change on farm animals. In addition, an estimate of $E R$ when introducing AMs is necessary. Therefore, we calculated the $E R$ on farm level and predicted the impact of global warming on ER for the near future, taking the year 2030 as an example.

We used a three-step process in order to assess the climate change related $E R$ in growing-fattening pigs and the potential of risk reduction with AMs. The risk is quantified by the reduction of the gross margin per animal place and year due to HS. The economic 
advantage of an AM can be compared in relation to the business-as-usual reference system. Due to the fact that industrial livestock is to a large extent maintained in the Cfb climate class covering large parts of Europe, North America, and China (Section 2.1), the results of this study undertaken for a site in Austria can easily be transferred to other areas in this temperate climate.

The AMs which are part of the ventilation system and cool the inlet air allow to substantially lower the degree of HS that can be expected inside growing-fattening pig buildings for the time horizon until 2030. These measures reduce the occurrence of HS even below the level of 1980. Despite also influencing the occurrence and severity of HS, other AMs were shown to be less effective. For the reference scenario, the $E R$ is estimated to be EUR 3.98 per year and animal place in 2030, with the VaR being EUR $6.81 \mathrm{a}^{-1}$ and $7.94 \mathrm{a}^{-1}$ per animal place for a 10 and 20 year return period, respectively. Using energy-saving AMs, ER can be reduced to the level of the year 1980 between EUR $0.03 \mathrm{a}^{-1}$ and EUR $1.02 \mathrm{a}^{-1}$ per animal place. In addition to animal welfare reasons, the economic benefits are relevant arguments to convince farmers to invest in precautions to reduce the economic risk caused by HS.

Due to the fact that the ammonia emissions for livestock farms have to be reduced in the future, emission abatement by AMs that are cooling the livestock building is an additional benefit of large societal importance.

In future studies, the combination of different adaptation approaches should be considered in order to derive information on an optimum design of multiple AMs. The combination of building-related measures with those involving management options and treatment of the inlet air seems to be particularly promising.

The ranking of AMs based on their effectiveness to reduce HS is a decisive step towards AM decision support for farmers. Subsequent research shall estimate the operating and investment costs of AMs as well as systematically assess the costs and benefits beyond climate change adaptation. It can also inform the design of efficient policies to support farm investments such as those included in Austria's strategic plan for the upcoming period of the EU Common Agricultural Policy (CAP). AMs require further innovations with respect to their effectiveness, resource intensity, costs, etc. The results in this paper can support farm-tech companies to determine the most promising fields of innovation.

Author Contributions: Conceptualisation, G.S., L.K. and W.Z.; methodology G.S., M.S., W.Z., S.J.H. and M.P.; modelling C.M., J.B., W.K., I.A. and K.A.; writing—original draft preparation G.S.; writingreview and editing G.S., M.S., W.Z., S.J.H., L.K., C.M., J.B., M.P., W.K., I.A., K.A. and I.H.-P. All authors have read and agreed to the published version of the manuscript.

Funding: The investigation was partly funded by the project PiPoCooL Climate change and future pig and poultry production: implications for animal health, welfare, performance, environment and economic consequences by the Austrian Climate and Energy Fund in the framework of the Austrian Climate Research Program (ACRP8-PiPoCooL-KR15AC8K12646). Open Access Funding by the University of Veterinary Medicine Vienna.

Institutional Review Board Statement: Not applicable.

Informed Consent Statement: Not applicable.

Data Availability Statement: Data sharing not applicable.

Acknowledgments: We thank the Austrian Meteorological Service ZAMG (Zentralanstalt für Meteorologie und Geodynamik, Vienna, Austria) for providing the meteorological data.

Conflicts of Interest: The authors declare no conflict of interest. 


\section{References}

1. Murray-Tortarolo, G.N.; Jaramillo, V.J. The Impact of Extreme Weather Events on Livestock Populations: The Case of the 2011 Drought in Mexico. Clim. Chang. 2019, 153, 79-89. [CrossRef]

2. COPA-COGECA. Assessment of the Impact of the Heat Wave and Drought of the Summer 2003 on Agricultural and Forestry; Comitêdês Organisations Professionalles de la Agricoles de la Communité Européenne/Comitê General de la Cooperation Agricole: Köln, Germany, 2004.

3. Nardone, A.; Ronchi, B.; Lacetera, N.; Ranieri, M.; Bernabucci, U. Effects of Climate Changes on Animal Production and Sustainability of Livestock Systems. Livest. Sci. 2010, 130, 57-69. [CrossRef]

4. Özkan, S..; Vitali, A.; Lacetera, N.; Amon, B.; Bannink, A.; Bartley, D.J.; Blanco-Penedo, I.; de Haas, Y.; Dufrasne, I.; Elliott, J.; et al. Challenges and Priorities for Modelling Livestock Health and Pathogens in the Context of Climate Change. Environ. Res. 2016, 151, 130-144. [CrossRef]

5. Bett, B.; Kiunga, P.; Gachohi, J.; Sindato, C.; Mbotha, D.; Robinson, T.; Lindahl, J.; Grace, D. Effects of Climate Change on the Occurrence and Distribution of Livestock Diseases. Prev. Veter.-Med. 2017, 137, 119-129. [CrossRef]

6. Morgan, E.R.; Wall, R. Climate Change and Parasitic Disease: Farmer Mitigation? Trends Parasitol. 2009, 25, 308-313. [CrossRef]

7. Wall, R.; Rose, H.; Ellse, L.; Morgan, E. Livestock Ectoparasites: Integrated Management in a Changing Climate. Veter.-Parasitol. 2011, 180, 82-89. [CrossRef] [PubMed]

8. van Dijk, J.; Sargison, N.; Kenyon, F.; Skuce, P. Climate Change and Infectious Disease: Helminthological Challenges to Farmed Ruminants in Temperate Regions. Animal 2010, 4, 377-392. [CrossRef]

9. Skuce, P.; Morgan, E.; van Dijk, J.; Mitchell, M. Animal Health Aspects of Adaptation to Climate Change: Beating the Heat and Parasites in a Warming Europe. Animal 2013, 7, 333-345. [CrossRef] [PubMed]

10. Hatfield, J.L.; Antle, J.; Garrett, K.A.; Izaurralde, R.C.; Mader, T.; Marshall, E.; Nearing, M.; Robertson, G.P.; Ziska, L. Indicators of Climate Change in Agricultural Systems. Clim. Chang. 2020, 163, 1719-1732. [CrossRef]

11. Gerber, P.; Steinfeld, H.; Henderson, B.; Mottel, A.; Opio, C.; Dijkman, J.; Falcucce, A.; Tempio, G. Tackling Climate Change Through Livestock; Food and Agriculture Organization of the United Nations (FAO): Rome, Italy, 2013.

12. Robinson, T.; Thornton, P.; Franceschini, G.; Kruska, R.; Chiozza, F.; Notenbaert, A.; Cecchi, G.; Herrero, M.; Epprecht, M.; Fritz, S. Global Livestock Production Systems; Food and Agriculture Organization of the United Nations (FAO): Rome, Italy, 2011.

13. Niamir-Fuller, M. Towards Sustainability in the Extensive and Intensive Livestock Sectors. Rev. Sci. Tech. de l'OIE 2016, 35, 371-387. [CrossRef]

14. Mikovits, C.; Zollitsch, W.; Hörtenhuber, S.; Baumgartner, J.; Niebuhr, K.; Piringer, M.; Anders, I.; Andre, K.; Hennig-Pauka, I.; Schönhart, M.; et al. Impacts of Global Warming on Confined Livestock Systems for Growing-Fattening Pigs: Simulation of Heat Stress for 1981 to 2017 in Central Europe. Int. J. Biometeorol. 2019, 63, 221-230. [CrossRef] [PubMed]

15. Schauberger, G.; Schönhart, M.; Zollitsch, W.; Hörtenhuber, S.; Kirner, L.; Mikovits, C.; Baumgartner, J.; Piringer, M.; Knauder, W.; Anders, I.; et al. Economic Risk Assessment by Weather-Related Heat Stress Indices for Confined Livestock Buildings: A Case Study for Fattening Pigs in Central Europe. Agriculture 2021, 11, 122. [CrossRef]

16. Fouad, A.M.; Chen, W.; Ruan, D.; Wang, S.; Xia, W.; Zheng, C. Impact of Heat Stress on Meat, Egg Quality, Immunity and Fertility in Poultry and Nutritional Factors That Overcome These Effects: A Review. Int. J. Poult. Sci. 2016, 15, 81-95. [CrossRef]

17. St-Pierre, N.; Cobanov, B.; Schnitkey, G. Economic Losses from Heat Stress by US Livestock Industries. J. Dairy Sci. 2003, 86, E52-E77. [CrossRef]

18. Dittrich, R.; Wreford, A.; Topp, C.; Eory, V.; Moran, D. A Guide towards Climate Change Adaptation in the Livestock Sector: Adaptation Options and the Role of Robust Decision-Making Tools for Their Economic Appraisal. Reg. Environ. Chang. 2017, 17, 1701-1712. [CrossRef]

19. Renaudeau, D.; Collin, A.; Yahav, S.; de Basilio, V.; Gourdine, J.-L.; Collier, R. Adaptation to Hot Climate and Strategies to Alleviate Heat Stress in Livestock Production. Animal 2012, 6, 707-728. [CrossRef] [PubMed]

20. Schauberger, G.; Hennig-Pauka, I.; Zollitsch, W.; Hörtenhuber, S.J.; Baumgartner, J.; Niebuhr, K.; Piringer, M.; Knauder, W.; Anders, I.; Andre, K.; et al. Efficacy of Adaptation Measures to Alleviate Heat Stress in Confined Livestock Buildings in Temperate Climate Zones. Biosyst. Eng. 2020, 200, 157-175. [CrossRef]

21. Schauberger, G.; Mikovits, C.; Zollitsch, W.; Hörtenhuber, S.; Baumgartner, J.; Niebuhr, K.; Piringer, M.; Knauder, W.; Anders, I.; Andre, K.; et al. Global Warming Impact on Confined Livestock in Buildings: Efficacy of Adaptation Measures to Reduce Heat Stress for Growing-Fattening Pigs. Clim. Chang. 2019, 156, 567-587. [CrossRef]

22. Vitt, R.; Weber, L.; Zollitsch, W.; Hörtenhuber, S.; Baumgartner, J.; Niebuhr, K.; Piringer, M.; Anders, I.; Andre, K.; Hennig-Pauka, I.; et al. Modelled Performance of Energy Saving Air Treatment Devices to Mitigate Heat Stress for Confined Livestock Buildings in Central Europe. Biosyst. Eng. 2017, 164, 85-97. [CrossRef]

23. Prettenthaler, F.; Köberl, J.; Bird, D.N. 'Weather Value at Risk': A Uniform Approach to Describe and Compare Sectoral Income Risks from Climate Change. Sci. Total. Environ. 2016, 543, 1010-1018. [CrossRef] [PubMed]

24. Toeglhofer, C.; Mestel, R.; Prettenthaler, F. Weather Value at Risk: On the Measurement of Noncatastrophic Weather Risk. Weather. Clim. Soc. 2012, 4, 190-199. [CrossRef]

25. Schauberger, G.; Piringer, M.; Petz, E. Steady-State Balance Model to Calculate the Indoor Climate of Livestock Buildings, Demonstrated for Finishing Pigs. Int. J. Biometeorol. 2000, 43, 154-162. [CrossRef] 
26. Schauberger, G.; Piringer, M.; Petz, E. Diurnal and Annual Variation of Odour Emission from Animal Houses: A Model Calculation for Fattening Pigs. J. Agric. Eng. Res. 1999, 74, 251-259. [CrossRef]

27. Schönwiese, C.-D. Praktische Statistik für Meteorologen und Geowissenschaftler, 5th ed.; Gebrüder Borntraeger: Stuttgart, Germany, 2013.

28. Beniston, M.; Stoffel, M.; Guillet, S. Comparing Observed and Hypothetical Climates as a Means of Communicating to the Public and Policymakers: The Case of European Heatwaves. Environ. Sci. Policy 2017, 67, 27-34. [CrossRef]

29. Orth, R.; Zscheischler, J.; Seneviratne, S. Record Dry Summer in 2015 Challenges Precipitation Projections in Central Europe. Sci. Rep. 2016, 6, 28334. [CrossRef] [PubMed]

30. Anders, I.; Stagl, J.; Auer, I.; Pavlik, D. Climate Change in Central and Eastern Europe. In Managing Protected Areas in Central and Eastern Europe Under Climate Change; Rannow, S., Neubert, M., Eds.; Springer: Cham, The Netherlands, 2014; pp. 17-30.

31. Beniston, M.; Stephenson, D.B.; Christensen, O.B.; Ferro, C.A.T.; Frei, C.; Goyette, S.; Halsnæs, K.; Holt, T.; Jylhä, K.; Koffi, B.; et al Future Extreme Events in European Climate: An Exploration of Regional Climate Model Projections. Clim. Chang. 2007, 81, 71-95. [CrossRef]

32. Della-Marta, P.M.; Beniston, M. Summer Heat Waves in Western Europe, Their Past Change and Future Projections. In Climate Variability and Extremes during the Past 100 Years; Springer: Singapore, 2008; pp. 235-250.

33. Della-Marta, P.M.; Haylock, M.R.; Luterbacher, J.; Wanner, H. Doubled Length of Western European Summer Heat Waves Since 1880. J. Geophys. Res. Earth Surf. 2007, 112, 11. [CrossRef]

34. Hendry, D.F.; Pretis, F. All Change! The Implications of Non-Stationarity for Empirical Modelling, Forecasting and Policy; Oxford Martin School Policy Paper Series: Oxford, UK, 2016.

35. Sulikowska, A.; Wypych, A. Seasonal Variability of Trends in Regional Hot and Warm Temperature Extremes in Europe. Atmosphere 2021, 12, 612. [CrossRef]

36. Sutton, R.T. ESD Ideas: A Simple Proposal to Improve the Contribution of IPCC WGI to the Assessment and Communication of Climate Change Risks. Earth Syst. Dyn. 2018, 9, 1155-1158. [CrossRef]

37. KTBL. Faustzahlen für die Landwirtschaft, 15th ed.; Kuratorium für Technik und Bauwesen in der Landwirtschaft, KTBL: Darmstadt, Germany, 2018; p. 1384.

38. Hoste, R. International Comparison of Pig Production Costs 2015: Results of InterPIG.; Wageningen Economic Research: Wageningen, The Netherlands, 2017.

39. BPEX. 2012 Pig Cost of Production in Selected Countries; British Pig Executive, Agriculture and Horticulture Development Board, AHDB Market Intelligence: Kenilworth, UK, 2013.

40. Edwards, W. Computing a Livestock Building Cash Rental Rate; Iowa State University: Ames, IA, USA, 2015.

41. Rojo-Gimeno, C.; Postma, M.; Dewulf, J.; Hogeveen, H.; Lauwers, L.; Wauters, E. Farm-Economic Analysis of Reducing Antimicrobial Use whilst Adopting Improved Management Strategies on Farrow-to-Finish Pig Farms. Prev. Veter.-Med. 2016, 129, 74-87. [CrossRef] [PubMed]

42. Mitter, H.; Schönhart, M.; Larcher, M.; Schmid, E. The Stimuli-Actions-Effects-Responses (SAER)-framework for Exploring Perceived Relationships between Private and Public Climate Change Adaptation in Agriculture. J. Environ. Manag. 2018, 209, 286-300. [CrossRef]

43. North, M.A.; Ouweneel, B. Global Risk of Heat Stress to Cattle under Climate Change. agriRxiv 2020, 37. [CrossRef]

44. Xiong, Y.; Yi, H.; Wu, Q.; Jiang, Z.; Wang, L. Effects of Acute Heat Stress on Intestinal Microbiota in Grow-Finishing Pigs, and Associations with Feed Intake and Serum Profile. J. Appl. Microbiol. 2019, 128, 840-852. [CrossRef] [PubMed]

45. Pearce, S.C.; Mani, V.; Boddicker, R.L.; Johnson, J.S.; Weber, T.E.; Ross, J.W.; Rhoads, R.P.; Baumgard, L.H.; Gabler, N.K. Heat Stress Reduces Intestinal Barrier Integrity and Favors Intestinal Glucose Transport in Growing Pigs. PLoS ONE 2013, 8, e70215. [CrossRef] [PubMed]

46. Kuehling, J.; Loewenstein, F.; Wenisch, S.; Kressin, M.; Herden, C.; Lechner, M.; Reiner, G. An In-Depth Diagnostic Exploration of an Inflammation and Necrosis Syndrome in a Population of Newborn Piglets. Animal 2021, 15, 100078. [CrossRef] [PubMed]

47. Mellor, D. Updating Animal Welfare thinking: Moving beyond the "Five Freedoms" towards "a Life Worth Living". Animals 2016, 6, 21. [CrossRef] [PubMed]

48. Schiavon, S.; Emmans, G. A model to Predict Water Intake of a Pig Growing in a Known Environment on a Known Diet. Br. J. Nutr. 2000, 84, 873-883. [CrossRef] [PubMed]

49. Muhlbauer, R.; Moody, L.; Burns, R.; Harmon, J.; Stalder, K. Water Consumption and Conservation Techniques Currently Available for Swine Production. In Proceedings of the Allen, D. Leman Swine Conference, Minesotta, MN, USA, 17 September 2011.

50. Cai, X.; Zhang, X.; Noël, P.H.; Shafiee-Jood, M. Impacts of Climate Change on Agricultural Water Management: A Review. Wiley Interdiscip. Rev. Water 2015, 2, 439-455. [CrossRef]

51. Fernandes, J.; Hemsworth, P.; Coleman, G.; Tilbrook, A. Costs and Benefits of Improving Farm Animal Welfare. Agriculture 2021, 11, 104. [CrossRef]

52. Ni, J. Mechanistic Models of Ammonia Release from Liquid Manure: A Review. J. Agric. Eng. Res. 1999, 72, 1-17. [CrossRef]

53. Schauberger, G.; Piringer, M.; Mikovits, C.; Zollitsch, W.; Hörtenhuber, S.; Baumgartner, J.; Niebuhr, K.; Anders, I.; Andre, K.; Hennig-Pauka, I.; et al. Impact of Global Warming on the Odour and Ammonia Emissions of Livestock Buildings Used for Fattening Pigs. Biosyst. Eng. 2018, 175, 106-114. [CrossRef] 
54. UN ECE. Framework Code for Good Agricultural Practice for Reducing Ammonia Emissions; United Nations Economic Commission for Europe: Brussels, Belgium, 2015.

55. Xu, L.; Penner, J.E. Global Simulations of Nitrate and Ammonium Aerosols and Their Radiative Effects. Atmos. Chem. Phys. Discuss. 2012, 12, 9479-9504. [CrossRef]

56. Backes, A.; Aulinger, A.; Bieser, J.; Matthias, V.; Quante, M. Ammonia Emissions in Europe, Part I: Development of a Dynamical Ammonia Emission Inventory. Atmos. Environ. 2016, 131, 55-66. [CrossRef]

57. Backes, A.M.; Aulinger, A.; Bieser, J.; Matthias, V.; Quante, M. Ammonia Emissions in Europe, Part II: How Ammonia Emission Abatement Strategies Affect Secondary Aerosols. Atmos. Environ. 2016, 126, 153-161. [CrossRef]

58. Brink, C.; van Grinsven, H.; Jacobsen, B.H.; Rabl, A.; Gren, I.-M.; Holland, M.; Klimont, Z.; Hicks, K.; Brouwer, R.; Dickens, R.; et al. Costs and Benefits of Nitrogen in the Environment. In The European Nitrogen Assessment: Sources, Effects and Policy Perspectives; Bleeker, A., Grizzetti, B., Howard, C.M., Billen, G., van Grinsven, H., Erisman, J.W., Sutton, M.A., Grennfelt, P., Eds.; Cambridge University Press: Cambridge, UK, 2011; pp. 513-540. [CrossRef]

59. Giannakis, E.; Kushta, J.; Bruggeman, A.; Lelieveld, J. Costs and Benefits of Agricultural Ammonia Emission Abatement Options for Compliance with European Air Quality Regulations. Environ. Sci. Eur. 2019, 31, 1-13. [CrossRef]

60. EEA. European Union Emission Inventory Report. 1990-2015 under the UNECE Convention on Long-Range Transboundary Air Pollution (LRTAP); European Environment Agency: Luxembourg, 2017.

61. EMEP/ EEA. EMEP/EEA Air Pollutant Emission Inventory Guidebook 2019. Part 3. Agriculture; European Environment Agency European Monitoring and Evaluation Programme: Luxembourg, 2019.

62. EU 2016/2284. Directive(EU) 2016/2284 of the European Parliament and of the Council of 14 December 2016 on the Reduction of National Emissions of Certain Atmospheric Pollutants, Amending Directive 2003/35/EC and Repealing Directive 2001/81/EC; EU: Brussels, Belgium, 2016.

63. Bokowa, A.; Diaz, C.; Koziel, J.; McGinley, M.; Barclay, J.; Schauberger, G.; Guillot, J.-M.; Sneath, R.; Capelli, L.; Zorich, V.; et al. Summary and Overview of the Odour Regulations Worldwide. Atmosphere 2021, 12, 206. [CrossRef]

64. Piringer, M.; Knauder, W.; Baumann-Stanzer, K.; Anders, I.; Andre, K.; Schauberger, G. Odour Impact Assessment in a Changing Climate. Atmosphere 2021, 12, 1149. [CrossRef]

65. Huynh, T.T.T. Heat Stress in Growing Pigs; Wageningen University: Wageningen, The Netherlands, 2005. 